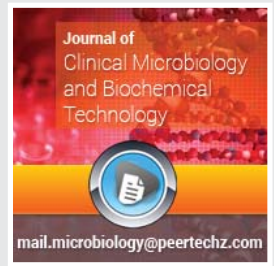

\title{
Bacterial aetiology of pani sold with popular street food Chaat in Bengaluru
}

\section{Vikyath Satish ${ }^{1 *}$, PM Giridhara Upadhyaya² and MS Kalpashree $^{3}$}

${ }^{1}$ Kempegowda Institute of Medical Sciences, College in Bengaluru, Karnataka, India ${ }^{2}$ Professor, Department of Microbiology, Kempegowda Institute of Medical Sciences, College in Bengaluru, India

${ }^{3}$ Senior Resident, Dermatology, Venerology and Leprosy (M.D), ACS Medical College, Chennai, India

Received: 26 February, 2021

Accepted: 08 March, 2021

Published: 12 March, 2021

*Corresponding authors: Dr. Vikyath Satish, Kempegowda Institute of Medical Sciences, College in Bengaluru, Karnataka, India, Tel: +91 9663715154; E-mail: VIKYATHJOURNALS@GMAIL.COM

Keywords: Chaat; Diarrhoea; E.coli; Food poisoning; Food safety; Hygiene; Pani puri; Street food https://www.peertechzpublications.com

\section{Check for updates}

\section{Abstract}

The primary focus of the study is to investigate the aetiology of the bacteria to bridge the gap between inadequate knowledge of bacterial growth in the pani and its role in food poisoning.

Aims and objectives: Isolation of bacteria in "pani" sold with popular street food chaat in Bengaluru

Identification of bacteria in "pani" sold with popular street food chaat in Bengaluru.

Procedure: 100 samples of pani purchased from the vendor in a parcel container was transferred to a sterile container of $30 \mathrm{~mL}$ capacity. The pani was streaked on MacConkey agar and Samonella Shigella agar and incubated at $37^{\circ}$ centigrade overnight. After overnight incubation, the plates of agar were observed for growth. If growth was observed, the isolated colonies were taken up for identification by performing the requisite biochemical reactions. If growth was not observed after overnight incubation, the plates were further incubated for 24 hours. If no growth was observed even on Selenite F broth subcultured plates, the pani was considered sterile and free of aerobic bacteria.

Results: Of the 100 samples collected, growth of Non Lactose fermenters were reported in $12 \%$; Lactose fermenters were $33 \%$ of which E.coli were $23 \%$ and Klebsiella were 14\%; Enterococci were $16 \%$; Suspected faecal contaminated samples were $51 \%$; Candida were $39 \%$ and no growth was reported in $4 \%$ of samples. The above coliform bacteria indicate faecal contamination and pose a threat to humans health. Caution must be exercised to prevent the diseases caused by them. This health hazard was found in street stalls as well as in established restaurants which reflect the magnitude of disease risk in the community. Regularised food inspection should be conducted by Health Inspectors to determine and ensure compliance of food safety standards.

Conclusion: The isolation of the above mentioned organisms is unacceptable by the minimum standards of safe and wholesome drinking water and food safety standards. The isolated enteric bacteria play a role in food poisoning with high mortality and morbidity, particularly in developing nations, and avoidance of street vended food is key to its prevention.

\section{Introduction}

Street foods is defined as "ready-to-eat foods and beverages prepared and/or sold by vendors and hawkers especially in street and other similar public places" [1].

Food poisoning refers to-Any disease of an infective or toxic nature caused by or thought to be caused by the consumption of food and water [2]. One such food in India is the Pani Puri (Gol Gappa) where in a hollow fried crisp is filled with seasoned boiled potato and dipped in a flavoured water containing tamarind and salt. The pani containing favourable ingredients for the growth of pathogenic bacteria including coliform organisms [3], serve as reservoirs in the spread of infection. 
The growth is augmented by the use of contaminated water from unsanitary sources and also by the dipping of the hand of the food handler in the cauldron containing the pani which could potentially transfer the bacterial flora into it. Moreover, take-away plastic covers used to parcel pani also serve as a source of infection Figures 1,2.

With millions of cases of food borne illnesses annually, unsafe food is a threat to human health and economies, affecting vulnerable and marginalised people, especially women and children, populations affected by conflict and migrants [4], making travellers diarrhoea the most common travel related infectious illness [5].

An estimated 600 million - almost 1 in 10 people in the world - fall ill after eating contaminated food and 420000 die every year, resulting in the loss of 33 million healthy life years (DALYs) [6].

The role of street food in the causation of Food Poisoning assumes a great deal of Public Health importance for the

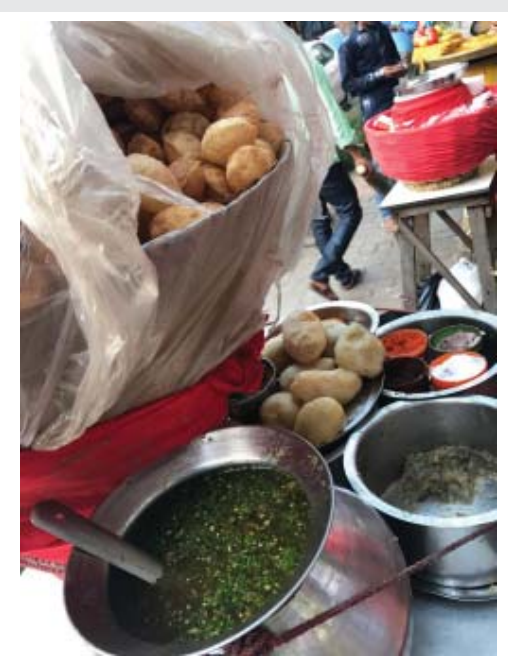

Figure 1: Street pani puri stall.

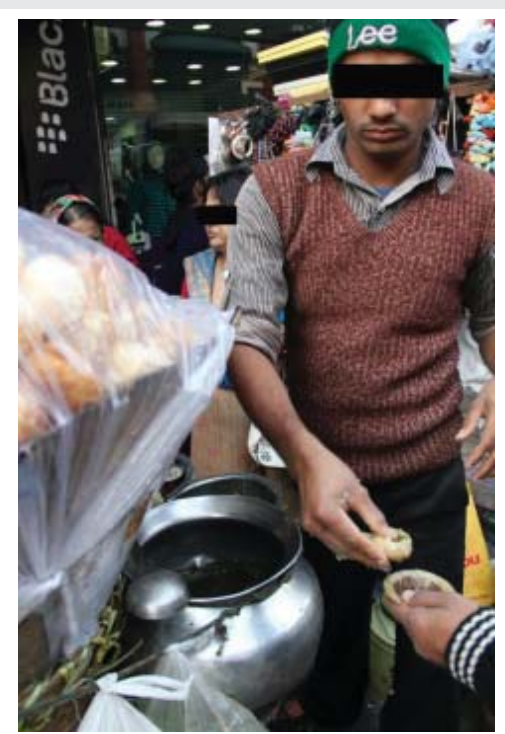

Figure 2: Food handler selling pani puri.
Country. The pani containing favourable ingredients for the growth of pathogenic bacteria including coliform organisms [7], serve as reservoirs in the spread of infection. The growth is augmented by the use of contaminated water from unsanitary sources and also by the dipping of the hand of the food handler [8] in the cauldron containing the Pani which could potentially spread the bacterial flora into it. Moreover, take away plastic covers filled with Pani also serve as a source of infection.

\section{Aims and objectives}

1. Isolation of Bacteria in pani sold with popular street food chaat in Bengaluru

2. Identification of Bacteria in pani sold with popular street food chaat in Bengaluru.

\section{Methodology}

The study was conducted in the Department of Microbiology in a tertiary healthcare hospital. Ethical clearance for the study was obtained from the Institutional Ethics Committee prior to the commencement of the study. This was a descriptive study with a sample size of 100 (purposive sampling) completed within a period of 2 Months. Pani collected from chaat vendors was included in the study and chaat food other than pani and vendors not having facility to parcel were excluded from the study.

\section{Procedure of the study}

Street vendors within a 10 kilometre radius around the institution were considered for the study. The confidentiality and anonymity of the vendor and sample collected was maintained by coding throughout the study. Pani was purchased in a parcel container and transferred to a sterile container of $30 \mathrm{~mL}$ capacity and stored in the refrigerator $\left(2^{\circ}-\right.$ $8^{\circ} \mathrm{C}$ ) after inoculation. The pani was streaked on MacConkey agar and Samonella Shigella agar and incubated at $37^{\circ} \mathrm{C}$ overnight. $1 \mathrm{~mL}$ of pani was inoculated into $2.5 \mathrm{~mL}$ Selenite-F Broth (Enrichment media) and incubated at $37^{\circ}$ centigrade overnight. After overnight incubation, the plates of agar were observed for growth and isolated colonies were taken up for identification by performing the requisite biochemical reactions like Indole, Triple Sugar Iron, Urease, Citrate, Mannitol motility, Oxidase, Sugar fermentation with Glucose, Maltose, Sucrose and Mannose. If growth was not observed after overnight incubation, the plates were further incubated for 24 hours. The Selenite F broth inoculated with the pani and incubated overnight was subcultured on MacConkey agar and Samonella Shigella agar and incubated at $37^{\circ}$ centigrade overnight. The subcultured plate was observed for growth the following day ( 24 hours). If growth was observed, the isolated colonies were taken up for identification. If no growth was observed on streaked plates, the pani was considered sterile and free of Aerobic bacteria Figure 3.

\section{Observation and results}

A total of 100 samples were utilised in this Study. The samples were inoculated into MacConkey agar and Salmonella 
Shigella agar. Biochemical reactions were performed to identify the bacteria and the results were analysed Figures 4,5 and Tables 1,2

\section{Statistics of growth of organisms}

Non Lactose fermenters- $12 \%$ of total samples collected

Citrobacter- $8 \%$ of total samples collected

Proteus- $2 \%$ of total samples collected

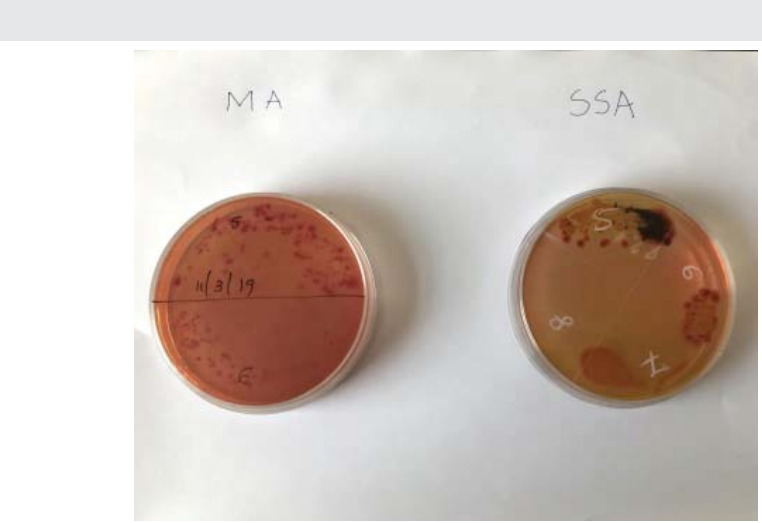

Figure 3: Growth observed in MacConkey agar and Samonella Shigella agar.

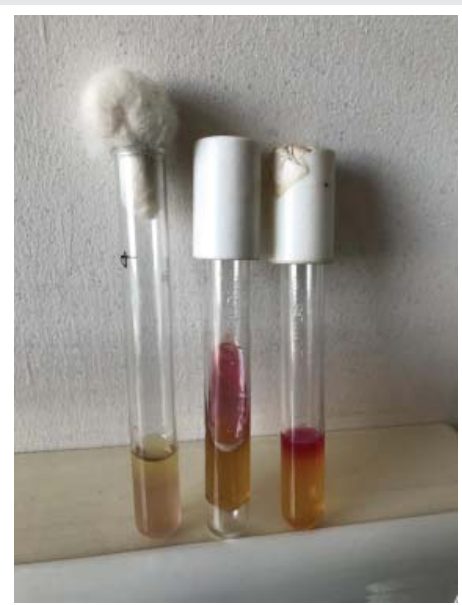

Figure 4: Biochemical reactions performed on the isolated organism.

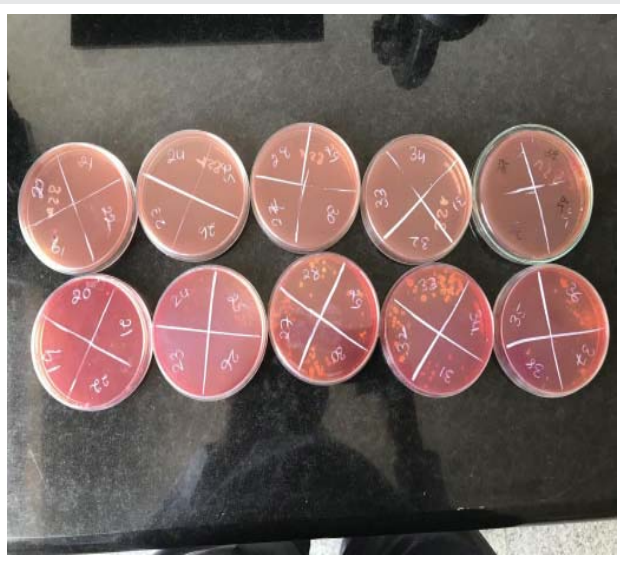

Figure 5: Batch of samples observed after overnight incubation in MacConkey agar and Samonella Shigella agar.
Table 1: The samples were inoculated into Salmonella Shigella agar.

\begin{tabular}{|c|c|}
\hline \multirow{2}{*}{ Growth of Organism } & $\begin{array}{c}\text { Number of Samples which showed growth } \\
\text { (In 100 Samples) }\end{array}$ \\
\hline Non Lactose fermenters & 12 \\
\hline Lactose fermenters & 33 \\
\hline E.coli & 23 \\
\hline Klebsiella & 14 \\
\hline Both E.coli and Klebsiella & 4 \\
\hline Coliforms (LF+NLF) & 40 \\
\hline Both LF and NLF & 5 \\
\hline Enterococci & 16 \\
\hline Candida & 39 \\
\hline Suspected faecal contamited & 51 \\
\hline samples & \\
\hline (LF+NLF+Enterococci) & 4 \\
\hline No Growth & \\
\hline
\end{tabular}

Table 2: The samples were inoculated into MacConkey agar.

\begin{tabular}{|c|c|}
\hline Growth of Organism & Number of plates of MacConkey agar \\
\hline Scanty $(1-10 \mathrm{CFU})$ & 30 \\
\hline Moderate $(11-100 \mathrm{CFU})$ & 48 \\
\hline Heavy $(>100 \mathrm{CFU})$ & 18 \\
\hline No growth & 4 \\
\hline
\end{tabular}

CFU- Colony forming units

Non fermentative gram negative bacilli other than Pseudomonas- $2 \%$ of total samples collected

Lactose fermenters- $33 \%$ of total samples collected

E.coli- $23 \%$ of total samples collected

Klebsiella- $14 \%$ of total samples collected

Both E.coli and Klebsiella in same sample $-4 \%$ of total samples collected

Coliforms $-40 \%$ of total samples collected

Both Lactose fermenters and Non Lactose fermenters in same sample- $5 \%$ of total samples collected

Enterococci-16\% of total samples collected

Candida-39\% of total samples collected

No Growth- $4 \%$ of total samples collected

Suspected Faecal contaminated samples-51\% of total samples collected.

\section{Discussion}

Pani puri is a famous street vended food in India. Pani is the flavoured water containing spices and salt used abundantly with popular Indian street food 'Chaat'. In this study, we aim to identify the contaminating bacteria present in the pani. As the spices and salt are a rather rare source of harbouring coliform bacteria, growth on culture media can be incriminated directly to the water source.

By definition, safe and wholesome water must be free 
from pathogenic organisms; But the samples of pani collected demonstrated growth of several disease causing organisms. The isolation of the above mentioned organisms is unacceptable by the minimum standards of safe and wholesome drinking water and food safety standards and thus serve as a nidus for infection to the population at risk.

Coliforms bacteria isolated such as Lactose fermenting bacteria Escherichia coli (diarrhoea in infants, children and travellers [9]) and Klebsiella [10], (diarrhoea in Immunocompromised individuals) and Non Lactose fermenting bacteria Citrobacter, Proteus and Non fermentative gram negative bacilli other than Pseudomonas present in a water sample provide a direct evidence of faecal contamination of the pani sample.

As observed in this study, pani laden with pathogenic organisms is not just limited to the street stalls. Established shops and restaurants serving pani claimed to be made from bottled mineral water also contained the same pathogens revealed on culture. This highlights the probability of carrier status in the food handler or the unhygienic preparation methods such as hand dipping into the pani cauldron.

The widespread contamination poses a disease threat to all sections of society irrespective of the socio economic status [11]. However, incomplete access to medical care and lack of essential medicines and oral rehydration solutions predispose the lower strata of society to increased morbidity and mortality. The prevalence of infection and related mortality [12], is also higher in children owing to their low resistance against infections.

In a practical setting, avoidance street vended food by the general population is challenging. Some steps that can be undertaken to ensure food safety such as improving personal hygiene of food handlers, usage of safe drinking water, appropriate preparation techniques and food hygiene, short holding time, usage of clean cutlery, clean parcel containers, identification and treatment of transmissible illness or carrier status in food vendor, building of food safety awareness in vendor, proper sanitation and waste disposal, usage of cooked vegetables, licensing of food stalls/vendors, regular health inspection and establishing legislature regarding street vended food.

Avoidance of high risk food such as street vended food and improperly cooked food and regularising eating pattern [13], play a significant role in preventing oneself from food borne infections. Research and development of an effective vaccine against E.coli [14] and other food borne pathogens assumes high priority particularly in developing nations.

Novel techniques like MALDI-TOF MS [15], Biosensors [16], Nucleic Acid-based Tests (NAT) [17], must be made available to rapidly detect food borne pathogens. Regularised food inspection should be conducted by Health Inspectors to determine compliance [18], with the law and gather evidence for enforcement in cases of noncompliance. Evidence states that the impact of health education intervention [19], on food safety and hygiene [20] and implementing a skill development program [21], in street vendors can prevent traveler's diarrhoea [22] and other food borne illnesses.

The transition from food toxins to food safety [23], is a gradual but yielding process for the safety and development of the nation and all necessary amends must be made to hasten the process.

\section{Future research}

The limitations of this research point towards topics to be addressed in the future. Due to the scope of the research undertaken, this study has potential limitations such as the isolated colonies were typed only to the genus level. Further studies can be done to identify the species of the isolated organism. Antibiotic sensitivity pattern was not determined for the isolated bacteria. This would provide us with insight for the clinical setting of treatment of the infection caused by these bacteria. A delay of half hour from point of sample collection to refrigeration must be considered as a favourable temperature for the growth of bacteria, causing a false increase in CFU count. However, in a practical setting, the pani is stored at room temperature for several hours at the food stall, thus raising the question of its significance. Correlation between the isolated bacteria from the sample of pani and the causal relationship to food poisoning was not established. Further studies can be conducted to identify the source of infectionwater source or food handler? This can only be determined by identifying the carrier status of the food handler which is beyond the scope of this study. Further research in the above mentioned lacunae will help bridge the gap between street food and its role in food poisoning.

\section{Conclusion}

The isolation of the pathogenic organisms is unacceptable by the minimum standards of safe and wholesome drinking water and food safety standards. The isolated enteric bacteria is incriminated in food poisoning with high mortality and morbidity, particularly in developing nations. Avoidance of street vended food is key to the prevention of food poisoning. The widespread contamination calls for regularised food inspection and emphasises the need for health education interventions on food safety in both the food handler and the consumer. Research and development of an effective vaccine against food borne pathogens and rapid techniques to detect food contamination will provide an upper hand in the fight against food poisoning.

\section{References}

1. Street foods. International Rice Commission Newsletter. 48. FAO of the UN Link: http://bit.ly/3qyjYCi

2. Kumar PJ, Clark ML (2017) Kumar \& Clarks clinical medicine. $9^{\text {th }}$ ed. Edinburgh: Elsevier 279. Link: https://bit.ly/3bxZu8l

3. Das M, Rath CC, Mohapatra UB (2012) Bacteriology of a most popular street food (Panipuri) and inhibitory effect of essential oils on bacterial growth. $J$ Food Sci Technol 49: 564-571. Link: http://bit.ly/2N1BS2u

4. International Food Safety Conference [Internet]. World Health Organization. World Health Organization. Link:: https://bit.ly/3tbQNqx

Citation: Satish V, Giridhara Upadhyaya PM, Kalpashree MS (2021) Bacterial aetiology of pani sold with popular street food Chaat in Bengaluru. J Clin Microbiol 
5. Kasper D, Hauser S, Jameson J, Fauci A, Longo D, et al. (2015) Harrison's principles of internal medicine. $19^{\text {th }}$ ed. New York: McGraw-Hill Medical Publ. Division 855. Link: http://bit.ly/3qzD62T

6. Food safety [Internet]. World Health Organization. World Health Organization. Link: https://bit.ly/3v9kCd1

7. Das M, Rath CC, Mohapatra UB (2012) Bacteriology of a most popular street food (Panipuri) and inhibitory effect of essential oils on bacterial growth. $J$ Food Sci Technol 49: 564-571. Link: https://bit.ly/2N1BS2u

8. Mathur P (2011) Hand hygiene: back to the basics of infection control. Indian J Med Res 134: 611-620. Link: http://bit.ly/3vdJlas

9. Steffen R, Hill DR, DuPont HL (2015) Traveler's diarrhea: a clinical review. JAMA 313: 71-80. Link: http://bit.ly/30tPnLx

10. Lääveri T, Vilkman K, Pakkanen SH, Kirveskari J, Kantele A (2018) A prospective study of travellers' diarrhoea: analysis of pathogen findings by destination in various (sub)tropical regions. Clin Microbiol Infect 24: 908.e9-908.e16. Link: http://bit.ly/3rLjSsc

11. Smith SM, Montero L, Paez M, Ortega E, Hall E, et al. (2018) Locals get travellers' diarrhoea too: risk factors for diarrhoeal illness and pathogenic Escherichia coli infection across an urban-rural gradient in Ecuador. Trop Med Int Health 24: 205-219. Link:: http://bit.ly/20zamKd

12. Wasihun AG, Dejene TA, Teferi M, Marugán J, Negash L, et al. (2018) Risk factors for diarrhoea and malnutrition among children under the age of 5 years in the Tigray Region of Northern Ethiopia. PLoS One 13: e0207743. Link: http://bit.ly/3vd5nQ8

13. Gupta NJ, Kumar V, Panda S (2017) A camera-phone based study reveals erratic eating pattern and disrupted daily eating-fasting cycle among adults in India. PLoS One 12: e0172852. Link: http://bit.ly/3vdK94A

14. Chakraborty S, Randall A, Vickers TJ, Molina D, Harro CD, et al. (2019) Interrogation of a live-attenuated enterotoxigenic Escherichia coli vaccine highlights features unique to wild-type infection. NPJ Vaccines 4: 37. Link: https://go.nature.com/3rAdFj1
15. Singhal N, Kumar M, Kanaujia PK, Virdi JS (2015) MALDI-TOF mass spectrometry: an emerging technology for microbial identification and diagnosis. Front Microbiol 6: 791. Link: http://bit.ly/3eoFAyq

16. Umesha S, Manukumar HM (2018) Advanced molecular diagnostic techniques for detection of food-borne pathogens: Current applications and future challenges. Crit Rev Food Sci Nutr 58: 84-104. Link: http://bit.ly/2N6tEGw

17. Mangal M, Bansal S, Sharma SK, Gupta RK (2016) Molecular Detection of Foodborne Pathogens: A Rapid and Accurate Answer to Food Safety. Crit Rev Food Sci Nutr 56: 1568-1584. Link: http://bit.ly/30tAybV

18. Manes MR, Kuganantham $P$, Jagadeesan $M$, Laxmidevi $M$, Dworkin MS (2016) A Step Towards Improving Food Safety in India: Determining Baseline Knowledge and Behaviors Among Restaurant Food Handlers in Chennai. J Environ Health 78: 18-25; quiz 117. Link: http://bit.ly/3qCMdzz

19. Dudeja P, Singh A (2017) A Longitudinal Study to Assess the Role of Sanitary Inspections in Improving the Hygiene and Food Safety of Eating Establishments in a Tertiary Care Hospital of North India. Indian J Community Med 42: 230-233. Link: http://bit.ly/2PR6zbS

20. Singh AK, Dudeja P, Kaushal N, Mukherji S (2016) Impact of health education intervention on food safety and hygiene of street vendors: A pilot study. Med $\mathrm{J}$ Armed Forces India 72: 265-269. Link: http://bit.ly/38m9YWz

21. Bhattacharya S, Talati S, Gupta AK, Malhotra S, Singh A (2019) Implementing a skill development program among food handlers in tertiary care hospital to improve their personal hygiene: A pilot study. J Educ Health Promot 8: 129. Link: http://bit.ly/38qo8FX

22. Shlim DR (2005) Looking for evidence that personal hygiene precautions prevent traveler's diarrhea. Clin Infect Dis 41: S531- S535. Link: http://bit.ly/3rxC88s

23. Siruguri V (2018) Journey from food toxins to food safety: Transition over a century in service of nation. Indian J Med Res 148: 488-495. Link: http://bit.ly/3IOfByG
Discover a bigger Impact and Visibility of your article publication with Peertechz Publications
Highlights

* Signatory publisher of ORCID

* Signatory Publisher of DORA (San Francisco Declaration on Research Assessment)

* Articles archived in worlds' renowned service providers such as Portico, CNKI, AGRIS, TDNet, Base (Bielefeld University Library), CrossRef, Scilit, J-Gate etc.

* Journals indexed in ICMJE, SHERPA/ROMEO, Google Scholar etc.

* OAI-PMH (Open Archives Initiative Protocol for Metadata Harvesting)

* Dedicated Editorial Board for every journal

Accurate and rapid peer-review process

Increased citations of published articles through promotions

* Reduced timeline for article publication

Submit your articles and experience a new surge in publication services (https://www.peertechz.com/submission).

Peertechz journals wishes everlasting success in your every endeavours.

Copyright: @ 2021 Satish V, et al. This is an open-access article distributed under the terms of the Creative Commons Attribution License, which permits unrestricted use, distribution, and reproduction in any medium, provided the original author and source are credited.

Citation: Satish V, Giridhara Upadhyaya PM, Kalpashree MS (2021) Bacterial aetiology of pani sold with popular street food Chaat in Bengaluru. J Clin Microbiol Biochem Technol 7(1): 020-024. DOI: https://dx.doi.org/10.17352/jcmbt.000047 